мера, а после снятия нагрузки давление продиффундировавшей во внутрь полимера среды разрывает полимер.

Существенное влияние оказывает и температура, при которой находится полимер при деформировании.

При эксплуатации баллонов с газом при низких температурах (от -4 до $-40{ }^{\circ} \mathrm{C}$ ) в баллоне возможно образование вакуума за счет перехода газа из газообразного состояния в жидкую фазу. В данном случае лейнер теряет устойчивость и начинает сжиматься в виде произвольной формы с образование складок. При таком сжатии лейнер за счет трения образовавшихся складок и ребер о стенки композитной оболочки получает механические повреждения в виде сквозных рваных отверстий, что приводит к катастрофической потере герметичности баллона.

Заключение. На основании вышеизложенного можно сделать следующие выводы.

Полиэтилентерефталат явяется очень нестабильным материалом с позиций коррозионного растрескивания под нагрузкой.

Основной причиной трещинообразования в полиэтилентерефталате являются технологические и эксплуптационные факторы.

Использование таких материалов для высоконагруженных конструкций крайне нежелательно.

В силу отмеченных явлений, происходящих с полиэтилентерефталатом, который используется в качестве базового материала для лейнера в конструкциях баллонов LPG надежность баллонов такой конструкции крайне низкая.

Практически аналогичные эффекты находят место и при использовании в качестве материала лейнера полиэтилена. В данном случаен проявляются еще дополнительные эффекты, связанные с структурой ПЕ.
Использование материалов типа ПЕ или ПЭТ в качестве основных для изготовления лейнеров баллонов давления является крайне нежелательным, особенно для баллонов высокого давления (рабочее давление более 20 бар).

Настоящая статья выполнена в рамках договора № 02.G25.31.0175 «Разработка новых импортозамещающих технологий производства металлокомпозитных емкостей и баллонов высокого давления с применением высокоточного позиционирования заготовок, микроплазменной сварки и программно-аппаратной интеграции и оптимизации параметров технологчческого процесса изготовления и испытаний», финансируемого Министерством образования и науки Российской Федерации.

Калинников Александр Николаевич, зав. лабораторией, Межотраслевой инжиниринговый иентр «Композиты России» МГТУ Им. Н.Э. Баумана, ФГАОУ ВО «Московский государственный технический университет имени Н.Э. Баумана (национальный исследовательский университет)». Россия.

105005, г. Москва, ул. 2-я Бауманская, 5.

Тел.: (499) 263-63-91.

Лебедев Игорь Константинович, канд. техн. наук, ООО «Системы армированных фильтров и трубопроводов» («САФИТ»). Россия.

Мороз Николай Григорьевич, канд. техн. наук, ООО «Системы армированных фильтров и трубопроводов» («САФИТ»). Россия.

141351, Московская область, Сергиево-Посадский $p$-н, д. Жучки, $2 \partial$.

Тел.: (495) 989-48-42.

Ключевые слова: баллоны высокого давления; полиэтилентерефталат; лейнер; композит; дефект.

\title{
OPERATIONAL FEATURES OF DESIGNS OF COMPOSITE CYLINDERS WITH A POLYMER LINER
}

Kalinnikov Alexander Nikolayevich, Head of laboratory, Intersectoral Engineering Center "Composites of Russia”, Bauman Moscow State Technical University. Russia.

Lebedev Igor Konstantinovich, Candidate of Technical Sciences, JSC "Reinforced Filters and Pipelines Systems" (SAFIT). Russia.

Moroz Nikolai Grygoryevich, Candidate of Technical Sciences, JSC "Reinforced Filters and Pipelines Systems" (SAFIT). Russia.

Keywords: high pressure cylinders; polyethylene terephthalate; linear; composite; defect.

This article analyzes the possible causes of damage (cracking) of polymer materials used for the manufacture of composite cylinder liners and assesses the reliability of LPG storage cylinders of this design of polyethylene terphthalate. The principal difference between the existing LPG cylinder designs of different manufacturers is the design of the outer protective casing and the inner sealing liner for the composite (fiberglass) shell. It is shown that main causes of cracking in polyethylene terephthalate are technological and operational factors.

DOI

удК 658.265

\section{ОБОБЩЕННЫЕ ПРЕДЛОЖЕНИЯ ПО РЕКОНСТРУКЦИИ ВОДОПОДГОТОВИТЕЛЬНЫХ УСТАНОВОК ДЛЯ ПРОИЗВОДСТВЕННЫХ КОТЕЛЬНЫХ}

\author{
КАТКОВ Данила Сергеевич, Саратовский государственный аграрный университет имени Н.И. Вавилова \\ ЖУкОВ Александр Викторович, Саратовский государственный аграрный университет \\ имени Н.И. Вавилова
}

В статье изложен опыт внедрения энергосберегающих технологий и систем автоматизации работы котельной, даны научно обоснованные рекомендации в области технико-экономического обоснования и реконструкции котельных, модернизации производственных котельных, обеспечениz безопасности и экологичности работы производственной котельной и ее соответствия требованиям надзорных органов.

Введение. Проблема эффективного отопления производственного предприятия с одновременным экономичным теплообеспечением различных тех- нологических процессов в настоящее время крайне актуальна [9]. Теплоснабжение промышленных предприятий - обеспечение теплом по месту его потреб- 
ления с помощью теплоносителя систем отопления, вентиляции, горячего водоснабжения промышленных зданий и технологических потребителей, используемое при конкретной необходимости. В данной работе будем исследовать автономные источники тепла промышленных предприятий [2, 3].

Цель исследования - обобщить прикладные знания в сфере реконструкции водоподготовительных установок в независимой схеме присоединения систем отопления промышленных потребителей и закрытой схеме присоединения систем горячего водоснабжения через собственные тепловые пункты.

Методика исследований. В качестве объекта исследования была выбрана система водоподготовки реконструируемой производственной котельной ООО «Газпром трансгаз Саратов» Приволжского ЛПУМГ в Воскресенском районе Саратовской области.

В качестве примера для расчета технико-экономических показателей принят стальной дымогарно-жаротрубный трехходовой низкотемпературный водогрейный котел мощностью 20 МВт [7, 8]. Назначение котла: для выработки теплофикационной горячей воды с температурой порядка $170{ }^{\circ} \mathrm{C}$ и рабочим давлением 1,6 МПа. Данный котел может работать на жидком и газообразном углеводородном топливе.

Этап 1. Химическое обследование воды, планируемой для заполнения котлового и отопительного контура: анализ ионного состава воды по основным показателям: кальций, магний, железо, карбонаты, гидрокарбонаты, щелочность, сульфаты, водородный показатель (pH). Химические анализы проводить по ГОСТ Р 51232-98 (2002) «Вода питьевая. Общие требования к организации и методам контроля качества».

Этап 2. Предварительный расчет технологических параметров, экспериментальный контроль рассчитанного режима комплексной обработки воды, контроль эффективности и уточнение параметров.

Этап 3. Регулярный эксплуатационный химический контроль соответствия водно-химического режима нормам, установленным на этапе разработки и зафиксированным в технологической документации.

Результаты исследований. В последние пять лет большинство промышленных предприятий России начинают все чаще сталкиваются с проблемами реконструкции открытых систем тепловых сетей на закрытые системы. Это не добровольные инициативы промышленников, а выполнение требований Федерального закона № 416-Ф3 «О водоснабжении и водоотведении» от 07.12.2011 г. и Федерального закона № 417-ФЗ от 07.12.2011 г., так как с 1 января 2022 г. вступит в действие запрет на эксплуатацию открытых систем тепловых сетей. Схемой теплоснабжения г. Саратова до 2027 г. предусмотрено, что «к 2019 году все потребители в зоне действия открытой системы теплоснабжения будут переведены на закрытую схему присоединения системы ГВС». Присоединение (подключение) всех промышленных потребителей к реконструируемым котельным будет выполняться «по независимой схеме присоединения систем отопления потребителей и закрытой схеме присоединения систем горячего водоснабжения через собственные тепловые пункты» [6].
Также в результате реализации проектов по переходу на закрытые схемы присоединения системы ГВС промышленными предприятиями г. Саратова предусмотрены реконструкции ВПУ, которые обеспечат сокращение расхода воды на подпитку тепловых сетей. По нашему убеждению, в результате реализации проектов достигается снижение объемов потребления теплоносителя в системах промышленного теплоснабжения, тем самым значительно повысятся их КПД, энергоэффективность, надежность и безопасность и существенно снизятся расходы на теплоснабжение промышленных предприятий.

В связи с вышеизложенным были выдвинуты обобщенные предложения по реконструкции ВПУ для промышленных котельных [1].

1. Для заполнения котлового контура (двухконтурная схема) рекомендуется использовать химочищенную умягченную воду не деаэрированную из передвижной установки ХВО. На наш взгляд, если котловой контур не имеет утечек, то вода для подпитки котлового контура практически не применяется и, как следствие, отсутствуют накипеобразование и коррозия в котле. Можно разрешить первоначальное заполнение котлового контура водопроводной водой без ХВО. Для убедительности, к примеру, использование воды в объеме $18 \mathrm{~m}^{3}$ на заполнение котлового контура не умягченной водопроводной водой питьевого качества с карбонатной жесткостью 5,3 г-экв/ $\mathrm{M}^{3}$ на поверхности нагрева котлов максимально может образоваться порядка 5,5 кг накипи (в перерасчете на $\mathrm{CaCO}_{3}$ ), что соответствует толщине не более 0,014 мм.

2. Обоснованно предлагается внедрить:

установки ультрафильтации серии УФС с номинальной производительностью одного блока от 12 до $125 \mathrm{~m}^{3} / \mathrm{ч}$;

установки обратного осмоса системы Росист производительностью от 1 до $70 \mathrm{~m}^{3} /$ ч;

блок концентрирования производительностью до $30 \mathrm{~m}^{3} /$ ч.

Предлагаемая система водоподготовки с использованием инновационных мембранных технологий обеспечит [4]:

1) сетевую воду с электропроводностью 5-8 См/см; жесткостью не более 4 мкг-экв/л; $\mathrm{SiO} 2<80$ мкг/л; $\mathrm{SDI}<1$;

2) снижение потребления воды на собственные нужды [5] за счет использования ультрафильтрации не менее $16 \%$; за счет использования обратного осмоса с блоком концентрирования не менее 7,5 \%; за счет использования мембранной установки не менее $20 \%$;

3) снижение эксплуатационных расходов;

4) возможность автоматизировать технологические процессы в сочетании с простотой обслуживания;

5) исключение длительного контакта обслуживающего персонала с высокотоксичными реагентами;

6) резкое снижение объема сточных вод.

Расчет технико-экономических показателей подтверждает экономическую эффективность модернизации ВПУ, а внедрение современных мембранных технологий позволит сократить затраты не менее чем в 6 раз (см. таблицу). 
Экономический эффект от предлагаемых рекомендаций, руб.

\begin{tabular}{|l|c|c|}
\hline $\begin{array}{l}\text { Tехнико-экономические } \\
\text { показатели }\end{array}$ & $\begin{array}{c}\text { Схема } \\
\text { до реконструкции }\end{array}$ & $\begin{array}{c}\text { Схема } \\
\text { после реконструкции }\end{array}$ \\
\hline $\begin{array}{l}\text { Затраты на исходную } \\
\text { воду }\end{array}$ & 410000 & 10416 \\
\hline Затраты на сбросы & 21244 & 34785 \\
\hline $\begin{array}{l}\text { Затраты на реагенты } \\
\text { для фильтров в год }\end{array}$ & 129667 & 10217 \\
\hline $\begin{array}{l}\text { Затраты на реагенты } \\
\text { для УФу в год }\end{array}$ & 0 & 6889 \\
\hline $\begin{array}{l}\text { Затраты на реагенты } \\
\text { для УОО в год }\end{array}$ & 0 & 29348 \\
\hline $\begin{array}{l}\text { Суммарные затраты } \\
\text { на реагенты для Н-ОН }\end{array}$ & 560911 & 91654 \\
\hline $\begin{array}{l}\text { Затраты на микро- } \\
\text { фильтры в год }\end{array}$ & 0 & 12246 \\
\hline $\begin{array}{l}\text { Затраты на досыпку } \\
\text { смол в год }\end{array}$ & 146291 & 14767 \\
\hline Суммарные затраты & 707202 & 118667 \\
\hline Суммарная экономия & \multicolumn{2}{|c|}{588535} \\
\hline
\end{tabular}

Заключение. Совершенствование методов водоподготовки и водно-химических режимов является необходимым условием дальнейшего повышения надежности и экономичности работы котельной в Приволжском ЛПУ МГ. Однако любой предлагаемый новый метод требует тщательного изучения и полной экспериментальной проверки, поскольку могут иметь место явления, оказывающие отрицательное воздействие на работу тех или иных элементов водоподготовительного и котельного оборудования и проявляющиеся по истечении некоторого, иногда длительного времени.

Причинами появления частных рекомендаций по широкому внедрению новых, якобы, вполне эффективных, но впоследствии оказавшихся недоработанными методов, технологий и режимов, могут быть недостаточный методический подход разработчика метода к проверке его эффективности и безопасности, недоучет каких-либо факторов, имеющихся на отдельных объектах и отрицательно влияющих на эффективность нового метода, но неизвестных разработчику и требующих или доработки метода, или установки граничных условий его применения.

\section{СПИСОК ЛИТЕРАТУРЫ}

1. Бушуев Е.Н., Еремина Н.А., Ждан А.В. Анализ современных технологий водоподготовки на ТЭС // Вестник Ивановского гос. энергетич. ун-та. - 2013. - № 1. C. 7-11.

2. Катков Д.С., Жуков А.В. Выбор способа обработки воды и режимов эксплуатации водоподготовительного оборудования для независимых систем локального тепло- снабжения // Актуальные проблемы и перспективы развития строительства, теплогазоснабжения и энергообеспечения: материалы VII очной Междунар. науч.-практ. конф. / под ред. Ф.К. Абдразакова. - Саратов, 2018. С. $143-146$.

3. Левин И.А., Катков Д.С. Предложения по реконструкции системы отопления вещевого рынка в г. Саратове с использованием гидрострелки // Актуальные проблемы и перспективы развития строительства, теплогазоснабжения и энергообеспечения: материалы VII очной Междунар. науч.-практ. конф. / под ред. Ф.К. Абдразакова. - Саратов, 2018. - C. $160-162$.

4. Первов А.Г. Современные высокоэффективные технологии очистки питьевой и технической воды с применением мембран: обратный осмос, нанофильтрация, ультрафильтрация. - Режим доступа: http://www.studentlibrary.ru/ book/ISBN9785930936919.html.

5. Первов А.Г., Андрианов А.П., Горбунова Т.П. Разработка мембранных технологий с уменьшенным расходом воды на собственные нужды // Водоснабжение и санитарная техника. - 2010. - № 6. - С. 13-21.

6. Приказ Министерства энергетики РФ от 23 декабря 2013 года № 920 «Об утверждении схемы теплоснабжения муниципального образования «Город Саратов» до 2027 года». - Режим доступа: http://docs.cntd.ru/ document/499079069.

7. Стрельников В.А., Брюнина О.Г., Катков Д.С. Тепловой расчет котельных агрегатов малой мощности: Методические указания к выполнению курсовой работы для студентов очной и заочной форм обучения специальности (направления подготовки) 270800.68 «Строительство». Саратов, 2013. - 60 c.

8. Теплообмен и теплообменные аппараты: учебнометодическое пособие для аудиторной и самостоятельной работы студентов очной и заочной форм обучения направлений подготовки 270800.62, 270800.68 Строительство (профиль подготовки «Теплогазоснабжение и вентиляция»), 140100.62, 140100.68 Теплоэнергетика и теплотехника (профиль подготовки «Энергообеспечение предприятий») / А.И. Кирюшатов [и др.]. - Саратов, 2015. - 124 c.

9. Федюнина Т.В., Материнский С.В. Модель автоматизированной системы анализа качества и энергоэффективности теплоснабжения зданий // Актуальные проблемы современной науки: сб. ст. Междунар. науч.-практ. конф. Уфа, 2014. - С. 44-47.

Катков Данила Сергеевич, канд. техн. наук, доцент

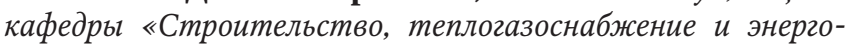
обеспечение», Саратовский государственный аграрный университет имени Н.И. Вавилова. Россия.

Жуков Александр Викторович, магистрант, Саратовский государственный аграрный университет имени Н.И. Вавилова. Россия.

410056, г. Саратов, ул. Советская, 60.

Тел.: (8452) 74-96-44.

Ключевые слова: вода; котел; мембранные технологии; ультрафильтрациия; обратный осмос.

\section{GENERALIZED PROPOSALS FOR THE RECONSTRUCTION OF THE PLANT FOR INDUSTRIAL} BOILER HOUSES

Katkov Danila Sergeevich, Candidate of Technical Sciences, Associate Professor of the chair "Construction, Heat and Gas Supply and Energy Supply", Saratov State Agrarian University named after N.I. Vavilov. Russia.

Zhukov Alexander Viktorovich, Magistrandt, Saratov State Agrarian University named after N.I. Vavilov. Russia.

Keywords: water; boiler; membrane technologies; ultrafiltration; reverse osmosis.
Within the framework of this article, it is made an attempt to share recommendations and experience in the following issues: the feasibility study and reconstruction of the boiler house, the modernization of industrial boiler houses, the introduction of energysaving technologies and automation systems for boiler house operation, the competent safety and environmental protection of the industrial boiler house and its compliance with the requirements of supervisory bodies. 